\title{
¿Cómo mejorar la perspectiva integrativa de los médicos clínicos? (II): Dos muestras descriptivas de grupos de reflexión "tipo Balint”
}

How to improve the integrative approach in clinicians (II): two descriptive samples of "Balint-type" reflection groups

JORGE L. TIZÓN

Psiquiatra y neurólogo, psicólogo y psicoanalista (SEP-IPA). Fundador y exdirector de las Unidades de Salud Mental de "Sant Marti-Nord" (Barcelona) y del Equipo de Prevención en Salud Mentaly Atención Precoz a los Pacientes en Riesgo de Psicosis (EAPPP, de la Atención Primaria de Salud de Barcelona). Exmédico de cabecera del Institut Catalá de la Salut, habilitado especificamente para ejercer como médico de medicina general en los Servicios Nacionales de Salud de la Unión Europea.

Profesor de la Universitat Ramon Llull (Barcelona).

Correspondencia: Jorge L. Tizón (jtizong@gmail.com)

Recibido: 06/05/2019; aceptado con modificaciones: 11/09/2019

Resumen: Los grupos Balint significaron una importante aportación para la formación y la formación continuada del personal sanitario, y, a mi entender, del personal de todos los servicios asistenciales. En ese sentido, las ideologías, políticas y economías "neoliberales" en el ámbito asistencial proponen otro modelo de asistencia y de "formación" (¿o deformación?) de los médicos y del personal asistencial. Su progresivo avance es una de las explicaciones fundamentales para el declive en el uso de procedimientos de formación integral, formación continuada y formación para la reparatividad. En el trabajo anterior se realizó una breve descripción de la difusión y extensión de los grupos "tipo Balint" tanto a nivel nacional como internacional, así como de sus cambios técnicos. Mi perspectiva actual es que los "grupos 
de reflexión", como sistemas de formación y contención del personal comunitario, siguen siendo una técnica o sistema que podría proporcionar importantes ayudas en la asistencia sanitaria y comunitaria clínica. Para contribuir a su conocimiento lo más directo posible, se incluyen dos muestras descriptivas: una transcripción completa de una sesión y un listado de los temas y aproximaciones realizadas en diversas sesiones de uno de dichos grupos.

Palabras clave: grupos, formación en salud mental, grupos Balint, grupos de reflexión, psicosomática, psiquiatría de enlace, relación médico-paciente.

\begin{abstract}
Balint groups represented an important contribution to the training and continuous education of health personnel, and, in my opinion, of the personnel of all healthcare services. In this sense, "neoliberal" ideologies, policies and economies in the health care field propose another model of doctors and health care personnel attention and "training" (or rather deformation?). Its progressive advance is one of the fundamental explanations for the decline in the use of comprehensive training procedures, continuous training, and training for reparativity. In the previous work, a brief description of the diffusion and extension of "Balint type" groups, both nationally and internationally, as well as of their technical changes, was made. My current perspective is that "reflection groups", as training and contention systems for community personnel, continue to be a technique or tool that could provide important aid in clinical health and community care. Here, to contribute to its knowledge as directly as possible, two descriptive samples are included: a complete transcription of a session and a list of the topics and approximations made in different sessions of one of these groups.
\end{abstract}

Key words: groups, mental health training, Balint groups, reflective practice groups, psychosomatics, liaison psychiatry, doctor-patient relationship.

¿Cómo mejorar la Perspectiva INTEgrativa de los médicos Clínicos? (II): Dos MUESTRAS DESCRIPTIVAS DE GRUPOS DE REFLEXIÓN “TIPO BALINT"1

E N EL TRABAJO ANTERIOR intentamos una breve descripción de los objetivos, téc- nicas, historia y difusión de los grupos Balint y los que hemos llamado "grupos de reflexión tipo Balint" (1). Para terminar esta breve introducción al tema, he creído que podría ser ilustrativo reproducir la Tabla 1, que representa una muestra de las características cualitativas de los temas y situaciones presentados en algunas de las primeras sesiones de uno de dichos grupos. Se trata de un "grupo de reflexión" en un centro de atención primaria a la salud. En el mismo sentido, en trabajos anteriores, citados en la primera parte del actual trabajo (1), pueden encontrarse intentos de

${ }^{1}$ Este trabajo toma algunos textos de trabajos anteriores del autor, citados en el texto y en la bibliografía. 
síntesis de los temas tratados en setenta y cinco sesiones pertenecientes a tres grupos de reflexión realizados en diversos centros de atención primaria (CAP).

TABla I

Una muestra esquematizada de las situaciones y problemas discutidos en un grupo de reflexión (con MIR y personal de plantilla) dentro de su primer año de existencia

\begin{tabular}{|c|c|c|c|c|}
\hline Sesión & Tipo de paciente & $\begin{array}{l}\text { Problema principal, } \\
\text { comprensión del caso }\end{array}$ & $\begin{array}{l}\text { Problema por el } \\
\text { que se presenta }\end{array}$ & $\begin{array}{c}\text { Otros, } \\
\text { descripción }\end{array}$ \\
\hline 10 & $\begin{array}{c}30 \text { años, mujer, } \\
\text { catarros frecuentes, } \\
\text { sinusitis, ¿Basedow?, } \\
\text { somatizaciones, } \\
\text { hija asmática... }\end{array}$ & $\begin{array}{l}\text { Somatizaciones } \\
\text { Celotipia el marido; } \\
\text { pasivo-agresiva ella }\end{array}$ & $\begin{array}{c}\text { Entender qué le pasa, } \\
\text { por qué sigue... } \\
\text {. Cómo "pasar a lo } \\
\text { psicológico" y quién }\end{array}$ & $\begin{array}{c}\text { "La } \\
\text { somatizadora } \\
\text { con marido } \\
\text { celotípico" }\end{array}$ \\
\hline 11 & $\begin{array}{c}10 \text { años, varón, } \\
\text { asma, bronquitis de } \\
\text { repetición, alergias } \\
\text { varias... } \\
\text { Múltiples depresiones } \\
\text { en la familia }\end{array}$ & $\begin{array}{l}\text { Hiper-reactividad } \\
\text { "no solo bronquial" } \\
\text {. Depresión infantil } \\
\text { "Inversión del rol" } \\
\text { con la madre }\end{array}$ & $\begin{array}{l}\text { Comprensión del niño } \\
\text { Qué hacer con la } \\
\text { madre y con el niño }\end{array}$ & $\begin{array}{c}\text { "El niño } \\
\text { biper-reactivo } \\
\text { deprimido" }\end{array}$ \\
\hline 12 & & $\begin{array}{l}\text {. Disociación } \\
\text { Funcionamiento } \\
\text { esquizoparanoide } \\
\text { del grupo } \\
\text {. Alternancia de } \\
\text { supuestos básicos } \\
\text { grupales }\end{array}$ & $\begin{array}{c}\text {. Falta de } \\
\text { puntualidad en el } \\
\text { grupo } \\
\text { Dinámica diferente } \\
\text { de los MIR y el } \\
\text { personal de plantilla }\end{array}$ & \begin{tabular}{|c|} 
"Los \\
supuestos \\
básicos en la \\
dinámica de \\
los grupos de \\
reflexión"
\end{tabular} \\
\hline 13 & $\begin{array}{c}80 \text { años, mujer, } \\
\text { cefaleica, miedo a } \\
\text { quedarse sola, visitas } \\
\text { a urgencias... }\end{array}$ & $\begin{array}{c}\text {.Vivir sola } \\
\text {. Morirse en la casa sin } \\
\text { nadie } \\
\text { ¿Muerte de un hijo que } \\
\text { conduce a depresión } \\
\text { y esta al aislamiento? }\end{array}$ & $\begin{array}{c}\text { Cefaleas de difícil } \\
\text { diagnóstico } \\
\text { "Estoy sola y mi } \\
\text { doctor no me quiere } \\
\text { ni ver"... }\end{array}$ & $\begin{array}{c}\text { "La abuela } \\
\text { cascarrabias } \\
\text { a la que nadie } \\
\text { bace caso" }\end{array}$ \\
\hline 14 & $\begin{array}{c}60 \text { años, varón, } \\
\text { alcohólico, mutilado, } \\
\text { con tres ancianas en } \\
\text { casa... }\end{array}$ & $\begin{array}{c}\text { Colusión entre } \\
\text { dificultades sociales y } \\
\text { manipulación de los } \\
\text { ancianos }\end{array}$ & $\begin{array}{l}\text { · ¿Cómo conseguir } \\
\text { que las ancianas } \\
\text { "ingresadas" en una } \\
\text { residencia ilegal } \\
\text { puedan ser atendidas } \\
\text { correctamente desde el } \\
\text { punto de vista médico } \\
\text { si los propietarios del } \\
\text { piso intentan evitarlo } \\
\text { con un casi-secuestro? }\end{array}$ & $\begin{array}{l}\text { "La residencia } \\
\text { geriátrica en } \\
\text { un domicilio } \\
\text { particular" }\end{array}$ \\
\hline
\end{tabular}




\begin{tabular}{|c|c|c|c|c|}
\hline Sesión & Tipo de paciente & $\begin{array}{l}\text { Problema principal, } \\
\text { comprensión del caso }\end{array}$ & $\begin{array}{l}\text { Problema por el } \\
\text { que se presenta }\end{array}$ & $\begin{array}{c}\text { Otros, } \\
\text { descripción }\end{array}$ \\
\hline 15 & $\begin{array}{l}60 \text { años, varón, } \\
\text { obeso, miocardiopatia } \\
\text { hipertensiva con } \\
\text { gran insuficiencia } \\
\text { cardíaca. } \\
\text { Terminal }\end{array}$ & $\begin{array}{c}\text { Entender la propia } \\
\text { muerte como proceso } \\
\text { de duelo difícilmente } \\
\text { elaborable. }\end{array}$ & $\begin{array}{c}\text { ¿Hay que decir "la } \\
\text { verdad" al paciente } \\
\text { terminal? }\end{array}$ & $\begin{array}{l}\text { "El terminal } \\
\text { que podía } \\
\text { deprimirse } \\
\text { demasiado" }\end{array}$ \\
\hline 16 & $\begin{array}{c}43 \text { años, mujer, } \\
\text { gitana, colitis } \\
\text { ulcerosa, con marido } \\
\text { somatizador.. }\end{array}$ & $\begin{array}{c}\text {. La agorafobia con } \\
\text { crisis de angustia como } \\
\text { causante de la actitud } \\
\text { paranoide en la relación } \\
\text {. En la discusión, parece } \\
\text { apuntarse que el marido } \\
\text { está delirando }\end{array}$ & $\begin{array}{l}\text { ¿Es posible mejorar } \\
\text { esta relación? } \\
\text { ¿Es un problema } \\
\text { personal o familiar? }\end{array}$ & $\begin{array}{l}\text { "La gitana } \\
\text { agorafóbica } \\
\text { con colitis } \\
\text { ulcerosa" }\end{array}$ \\
\hline 17 & $\begin{array}{c}43 \text { años, mujer, } \\
\text { insomnio, marido } \\
\text { con varias visitas a } \\
\text { urgencias... }\end{array}$ & $\begin{array}{c}\text { ¿Por qué no se duerme } \\
\text { uno? } \\
\text { El marido, con un } \\
\text { dolor crónico, "me vuelve } \\
\text { loca por las noches" }\end{array}$ & $\begin{array}{l}\text {. Un insomnio que } \\
\text { no se comprende: } \\
\text { ¿hay que dar BZD? }\end{array}$ & $\begin{array}{l}\text { "La esposa } \\
\text { del paciente } \\
\text { con dolor } \\
\text { crónico" }\end{array}$ \\
\hline
\end{tabular}

Lo que he venido diciendo hasta ahora podría ser ilustrado aquí con el recuerdo de una sesión de grupo de reflexión "tipo Balint" publicable con ciertos cambios, orientados a proteger la privacidad de los miembros del grupo y de los consultantes. Incluyo, pues, la trascripción revisada de la séptima sesión de un grupo de reflexión realizado en un centro de atención primaria a la salud.

Los componentes de este grupo de reflexión "tipo Balint" eran 7 médicos (3 médicos de familia y 4 pediatras), 7 enfermeras, una trabajadora social y dos psiquiatras (uno de ellos el coordinador y otro en formación en grupos "tipo Balint"). Las notas resultan más amplias de lo acostumbrado (y sesgadas hacia las intervenciones de salud mental), probablemente porque fue este segundo psiquiatra el que recogió el esquema de las intervenciones para completarlo tras terminar la sesión. Por otra parte, como muestran sus notas, aún no conocía el nombre de varios de los participantes.

Me he decidido a incluir esta sesión, en primer lugar, porque ocurrió hace más de una docena de años, con lo cual ni los participantes ni los consultantes corren excesivo peligro de ser reconocidos. En segundo lugar, sin embargo, porque se centra en un tema que en los ańos posteriores ha acabado recibiendo una gran importancia científica y mediática que continúa en nuestros días: el de la "violencia doméstica" o "de género" y los abusos sexuales en la infancia, un tema que he tratado recientemente desde una perspectiva creo que alternativa a las habituales (2). En tercer lugar, porque precisamente las sociedades científicas y asistenciales españolas y catalanas de 
medicina de familia han intentado e intentan hacer prevención sobre el tema. Sus órganos científicos (el Programa de Actividades Preventivas y de Promoción de la Salud de la Sociedad Española de Medicina de Familia y Comunitaria, el PAPPS de la SEMFyC) han publicado sendos protocolos de actuación sobre el mismo (3-5). Con todos los errores e insuficiencias que muestra, les expongo la sesión, recogida con esas notas tomadas, como he dicho, por otra persona diferente del propio coordinador (JLT).

Consuelo (enfermera) dice que quiere presentar un caso. Que es una lástima que sea la única que viene al grupo de la Unidad Básica Asistencial (UBA: unidad más o menos funcional formada por médico titular, enfermeralo, MIR y, en ocasiones, enfermerola-residente).

Rosa (enfermera) se extiende hablando del problema de las UBAs en el grupo: Es una lástima que no estén todos los componentes de la Unidad Asistencial para realizar la discusión de algunos casos. Luego siempre quedan las cosas asi, algo "cojas", y no se puede aprovechar suficiente....

Consuelo: Traigo un caso de Alba (la MIR) y mio que, además de impactarme, es de abuso. Es una señora de 49 o 50 años, que ya hace tiempo que nos viene, pero que ahora le ha contado a Alba unas cosas... Bueno, ¿empiezo?

Marita (pediatra): Sí.

Consuelo: Es andaluza, vino muy pequeñita, con 6 años, a vivir con sus tíos. La tía, no sé, creo que era hermana de su madre. Ella, la paciente, hizo los estudios aqui y es profesora de un colegio. En la historia pone que tiene trastornos depresivos, y va a un psiquiatra privado. Cada final de curso tiene una crisis, incluso alguna vez se le ha dado la baja. Siempre pensamos: “Pobres niños del colegio!”. Ya hace tiempo, años, que ha muerto la tía que la acogió, pero no el tío...

Tonia (enfermera de pediatría): ¿Es soltera?

Consuelo: Sí, es soltera. Desde que murió la tía están solos el tío y ella. Ella siempre está triste, siempre, en el hablar y en el hacer. Va como víctima y es difícil, muy difícil de atender, de tratar, de soportar... Corrieron rumores en el Centro, yo los oi no sé de quién, de que entre el tío y ella hubo un problema de violación, hace muchos años... Pero no quedó claro, ni yo estoy segura... Pero el otro dia se agredieron "a matar", se pegaron, con mordiscos y todo. Algo muy bestia: lo sabemos porque vinieron a que la curáramos a ella. Algo muy bestia: fue Alba a domicilio y se estaban pegando encima de la cama. La paciente le explicó entonces, o después, con las curas, que ya no puede más, que querría irse a vivir fuera, que incluso tiene un piso, pero que en el lecho de muerte le prometió a su tía cuidar siempre de su tio, y que por eso no lo deja. Que ahora se ha comprado esa casita, y está deseando irse a ella, pero el tío no quiere que se vaya y por esto no se va. Bueno, el caso es que el otro día se pegaron... Y entonces volvimos a pensar el caso de la posible violación de hace años: "violación" entre comillas... Porque es que también dice 
que tuvo un niño hace años, pensamos y parece que del tío, que dio en adopción. Pero todo esto lo dice ahora. Este es el problema: que salga a la luz a los 50 años. Dice que durante los nueve meses de embarazo no salía de casa y que luego dio al hijo en adopción.

Tonia: ¿La tía lo sabia?

Marita: La tía está muerta.

Consuelo: Si, pero parece que si que lo sabia.

Otra enfermera: Pero ¡tienen relaciones sexuales?

Consuelo: Sí. Es duro que después de violarla y hacerle un hijo, continúe con él. Varios, de forma entrecortada, complementándose: ¡Pero eso es incesto!

Consuelo: Sí, bueno, claro.

Pediatra 1: ¿Trabaja?

Consuelo: Sí, es maestra.

Pediatra 1: ;Ay, es verdad!

Ma Carmen: Parece una novela de la radio.

Consuelo: Escuché, solo escuché. No sabia qué decir. ¡Qué vas a decir! Pero me sonó muy mal. $Y$ me dio mucha rabia por el trabajo que nos ha ido dando cada año y a cada momento con sus crisis... Y encima, sin poder entrar a fondo, porque está el psiquiatra privado de por medio... Que la hincha a fármacos, por cierto. $Y$ nosotros, a "pasárselos". ;Y ahora esto! Pero la he vuelto a citar, claro. Y más que nada es que como tú (al coordinador del grupo), el otro dia, decías que traemos cosas muy patológicas, tal vez porque las tenemos que aguantar y aguantar... Tal vez por eso en este grupo salen estos casos... El caso es que pensé que tenía que traerla... Porque, además, no sé qué hacer, y a salud mental ya va, bueno, al psiquiatra ese, que no sé quién es, privado, claro.

Lola (pediatra): Hay casos así. Hay un caso real, que los conozco, que no podian tener hijos, asi que decidieron, o decidió, no sé cómo, que los tendría y él los tuvo. Dos, con la sobrina. Y abora son mayores que yo.

Consuelo: Sí, porque es que, además, ella dice: "Oye, yo le sigo queriendo, pero no puedo vivir con él". jLo expresa de esa manera! Es una mujer que siempre tiene crisis, crisis de sofocaciones o de angustia, y se queja de muchas cosas en las crisis. Pero esto lo explica de una forma, no sé, como con euforia.

Rosa: ¿Al explicar eso?

Consuelo: No, sí, quiero decir que con una entereza, de una forma... Cuando explicaba que su tía se moría, parece que estaba contenta. Lo pensamos y comentamos ya hace años. ¡Será "capulla”, nos deciamos, que parece que está contenta!

Ma Carmen: Pero era una tía de sangre, la de ella, ¿no?

Consuelo: Sí, ella era la hermana de la madre. Pero es como si a lo largo de los años haya pensado: "Quiero, no quiero", con sentimientos de culpa, como si todo se le hubiera mezclado. La versión es la de ella, y no sabemos otra. Pero, según ella dice, su madre vive en el pueblo, vive aún. Pero ella dice que no va a verla porque el tío no quiere ir al 
pueblo porque se lleva mal con la madre... ; Que no me extraña! Pero al mismo tiempo la madre tampoco hizo nada por conectar con ella. Quizá ahora sea el momento más sano de esta señora, ahora que lo vuelvo a pensar.

Pediatra 1: ¿Por qué vino a vivir con los tíos?

Consuelo: No se sabe.

Enfermera 2: Nunca viene acompañada por el tío.

Consuelo: Sí, más bien ella viene a acompañarle a él, cuando él viene al médico. Es una relación muy rara.

Ma Carmen: Es un triángulo.

Consuelo: No, la tía ya ha muerto.

Ma Carmen: Sí, bueno. Pero hasta entonces era un triángulo y luego en la cabeza de ella sigue siéndolo. Un triángulo, e incestuoso. ¡Puff! (apesadumbrada-hastiada-rechazante).

Consuelo: En algún momento nos dijo, encima, que para que él, el tío, no crea que ella se va a ir, que le va a abandonar (porque ha puesto la casita, la casita nueva, una comprada con sus ahorros, a la que se quiere ir)... Para que no se crea que le va a abandonar, pues se la ha puesto a nombre del tio. ;Es que lo mezclan todo, sentimentalmente, económicamente...! Todo.

JLT: Alguno de vosotros ha comentado el tema del incesto: es un tabú. Ha salido en el grupo y ha ido creciendo esa idea. Con el rechazo que lleva aparejado, porque es un tabú en nuestra sociedad. Pero entonces produce tanto rechazo que dificulta pensar. $Y$ en este caso, como en otros, es muy importante pensar a qué edad ha sucedido y en el grado de parentesco real... Está bien que alguien en el grupo haya preguntado otra vez para asegurarse del parentesco, de la sangre: porque ha dicho de la sangre. Vale la pena preguntarse por nuestras fantasias y por sus fantasias. Por ejemplo, al principio has dicho que no sabias si era o no la hermana de la madre, pero cuando te lo han preguntado directamente has dicho que si. Porque, al menos en vuestra fantasia, y probablemente en la suya, y en su culpa, no es solo un triángulo: es un triángulo incestuoso, como en el otro caso que también ha salido en el grupo. Aceptado o no, legal o no, pero es la fantasía la que lo convierte en tan patógeno y lo hace ser tan rechazado. Has comentado tú: aceptado o no, es un triángulo incestuoso. Es decir, un triángulo imperdonable, una culpa imperdonable e insoportable.

Marita: El tuyo, tu paciente, es que es un polígamo.

Consuelo: Un detalle: el Dr. M, el médico de familia (que no pertenece al Balint), le quiso hacer un árbol genealógico, de la mujer, de la familia. Le costó, pero salió un recién nacido muerto, un niño muerto a los tres o cuatro dias... Y ahora con esto, yo creo que ese era el niño y ellos dos eran los padres y el niño.... (Se entrecorta. No puede seguir).

JLT: Murió en su mente: tal vez era un fruto del demonio, de la culpa, del tabú... 
Marita: Pero ¿lo dio en adopción ella o se lo quitaron?

Consuelo: No se sabe, pero podría ser cualquiera de las dos cosas.

Tonia: A mi no me llama tanto la atención que a los 6 años viniera a Barcelona. Yo vine a los 18 años a vivir con mis tías.

(Expresiones de temor en el grupo, de reprochar que se compare el tema, hasta que una pediatra logra hablar por encima de los comentarios a media voz):

Marita: Pero no a los 6. No es lo mismo.

Tonia: Antes era normal, se enviaban mucho más los hijos con los familiares de la ciudad, con los que podian cuidarlos, con los que podían vivir con menos miseria, con los que podían cuidarlos para darles estudios...

Consuelo: Lo que me cuesta pensar es que la madre no se enterara de todo esto: su hija tiene un hijo y ella no se entera. Aunque, como afirma ella, estuviera encerrada en casa los nueve meses.

JLT: Como poco, indica que en nueve meses no vio a su hija para nada. Y ya las cosas no estaban tan mal: España no era la España de la postguerra, se viajaba y se podía viajar, y la chica, además, estudiaba. Tal vez estuviera ya terminando los estudios de Magisterio en la Escuela Normal. Eso nos hace pensar que hay quien no sabe y hay quien "decide", entre comillas, no saber.. Difícil diferenciar entre negación y disociación. ¡Y qué duro debe de ser sentirse hija de una madre que prefiere no saber qué pasa con el tio! Que hace como que no se entera de lo que está pasando y que no te reclama para que vuelvas ya... Recordad lo que medio en broma hemos comentado algunos dias: a menudo la ingenuidad no es sino una perversión egosintónica.

Risas. Comentarios múltiples: ¿Cómo?

JLT: El ingenuo listo usa una especie de "chollo", una disociación extrema, mediante la cual puede vivir como si no se enterase de lo que es muy dificil o imposible de resolver. No se entera de nada. ;Problemas fuera!

Consuelo: Si, ahora lo entiendo. Si hubiera tenido la suerte de que la madre reaccionase, la tía tal vez hubiera reaccionado también. $Y$ ahora no existirían tantos problemas. Y problemas, creo, sin solución. Quizá hubiera habido un lio mucho antes, pero no este "cacao" de ahora.

Ma Carmen: ¿Y por qué es profesora? ¿Lo ha escogido ella? ¿Cómo puede ser?

Alfons (un médico de familia): No es tan raro, no es tan raro.... En realidad, es bastante frecuente...

JLT: Porque la vocación de maestro, como, por cierto, la de médico, psicólogo, enfermera, se prestan mucho a la reparación, pero también....

Ma Carmen: Ya entiendo: como una madre frustrada, se dedica a la enseñanza...

JLT: No, tal vez no tan directo... Tal vez intenta reparar dando cauces, cuidando niños, enseñando a niños lo que siente que no pudo reparar a tiempo dentro de ella. $O$ tal vez, como dices, está identificada con una madre frustrada, que no pudo o no fue 
capaz de soportar a su hija. Tal vez porque ella sí sabe por qué y nosotros no. Pero, de todas formas, eso si que es patógeno, para la madre y para la hija: el verse separada de la madre y que la madre no la reclama ni en los peores momentos. Seguro que aumenta el sentimiento de indefensión: ni tu madre está por ti.. Qué difícil vivir así.. Se necesita apoyarse rápidamente en alguien, como sea, quien sea... No será peor que la propia madre de la fantasia... Y es un conflicto que no se puede elaborar nunca totalmente: por eso tiende a la sublimación... y a la seudoreparación. Por eso durante años, decenios, por ejemplo en la España del franquismo, ponian a cuidar a los niños pequeños, sobre todo en los orfelinatos, a chicas y mujeres con ciertas discapacidades y trastornos mentales, a las que se consideraba "tontitas y enfermas diversas". Era relativamente frecuente en orfelinatos, guarderias o "casas cuna" y en otras profesiones...

Todos: ¿Qué? ¿Cómo?

JLT: Porque, además, a ese tipo de personas les suele gustar. En algunos casos tiene que ver con intentos, casi siempre fallidos, de reparación, de arreglar fuera lo que no se puede arreglar en la mente ni en la relación con una madre tan cruel que abandonó... "Por cruel que sea el tío, no será más que la madre". Mejor dicho: incluso hay la tendencia a que sea un otro como la madre, a escoger un "apoyo" similar, necesario pero cruel.

Varios: Pero eso de "tontitas"...

JLT: Monjas y mujeres escogidas asi cuidaron a los niños huérfanos y "sin posibles" en la España del franquismo: como no iban a conseguir marido, ni título, ni otro lugar en la sociedad... Y, ciertamente, muchas personas con déficit intelectuales, incluso con sindrome de Down, por el mayor contacto con la afectividad, pueden ser muy cariñosas cuidando niños... Pero también pueden confundirse mucho, o errar en decisiones, o estimular poco, o tener raptos agresivos incontrolados. Pero fuera de situaciones limites iparecen tan cariñosas! (con cierta ironía). Pensad en las mamás orangután: es impresionante cómo cuidan a sus hijos. $Y$ en Catalunya también todo esto es bastante típico, al menos me vienen a la mente tres o cuatro pacientes depresivas graves que habéis presentado y que inmigraron a Catalunya huyendo de situaciones sociales o psicosociales graves y estudiaron Magisterio. Se podría decir que escogieron al tiempo la carrera y la depresión como carrera --aunque esta no la escogieron, claro está.

$Y$ esto nos hace ver el caso desde otra perspectiva: el problema no es tanto que tengan relaciones sexuales las personas entre ellas, incluso con diferencias de edad, incluso más o menos incestuosas... Que eso del incesto, además, en este caso sería discutible. Pero lo importante es que resulta bastante natural viviendo bajo el mismo techo, y más una niña abandonada de la madre, abandonada por sus padres. El problema mayor es cómo y por qué se mantienen estas relaciones años y años... Al fin y al cabo, incluso el incesto es mucho más frecuente de lo que pensamos. Pero esas relaciones, que son tan "culpógenas" para la paciente, ¿por qué se siguen manteniendo años y años?

Marita: ¿Porque él es un perverso? 
Jordi: ;Convivir con la familia fuera del pueblo es de lo más normal!

Marita: ... (Continuando). ...Pero en este caso parece que ha sido su segunda pareja: que debe haber tenido relaciones sexuales con las dos bajo el mismo techo. Es duro.

JLT: E incluso no sabemos si era jovencita, mayor, o si todo esto comenzó ya de niña, cuando vino tan sola y probablemente abandonada. Recordad las vinculaciones masoquistas que se establecen entre los niños abusados y el abusador, y que a veces hemos visto en este barrio...

Consuelo: Algo de eso si me ha explicado. Ahora lo recuerdo. ;Es verdad! Me contó, y no sabemos si es verdad, me contó que ya el primer día que llegó se despertó con la mano de su tio en su pecho. Pero ¿se puede acordar de esto? ¿No será tan solo una fantasía que tiene en su cabeza?

Marita: Si, es verdad. Yo creo que si que se puede acordar.

Alfons: A lo mejor al despertarla le tocó en el pecho pero sin ninguna intención y a ella le ha quedado esto y lo vivió o lo recuerda así..

JLT: Estas últimas reflexiones del grupo también amplian el campo... Nos hacen comprender de forma más compleja las relaciones humanas: ¿es fantasía?, ¿fue realidad? Puede ser un recuerdo, pero es el recuerdo de algo "perverso". Puede ser una fantasía de entonces o de ahora, pero, en todos los casos, lo que queda claro es que ella vive esa relación como una relación perversa... que ella misma perpetúa. Y con alguien a quien voluntariamente, "iibremente", sin que nadie la obligara, ha prometido "cuidarle hasta la muerte". Ahora lo tenemos más claro: ella lo vive como una relación de esas que llamamos "perversas"...

Alfons: El adulto lo vive de una manera y el niño de otra.

JLT: Pero lo importante no es la conducta, ni siquiera la conducta social, a pesar de lo que digan los conductistas: lo realmente patógeno son las fantasias y sentimientos con los que se vive la realidad. Y que llevan a la repetición, pueden crear una auténtica compulsión a la repetición, como ya decía Freud.

Ma Carmen: Yo llevo un niño de 6 años que está en San Juan de Dios por abuso sexual. Dice que su tio le tocaba. La madre se ve que habia recibido abusos sexuales de pequeña. Los 5 hermanos, chicos y chicas, habian recibido abusos sexuales, pero nunca habian dicho nada. Es ahora cuando lo han contado. Cuando la niña dijo que su tío, el hermano de su madre, la habia tocado con el dedo en los genitales... La madre lo denunció enseguida. Creo que revivió su propia historia y se decidió... Gracias a la hija. Pero luego han aducido que la niña dice que tenía un agujero en el pantalón y que su tío solo se lo tocó para señalárselo... Y la propia madre ha retirado la denuncia.

JLT: Una niña a la cual le miran un agujero del pantalón... Aun suponiendo que solo fuera eso, que no fuera un abuso directo... Pero una niña con un entorno erotizado puede vivirlo de forma diferente. No sabemos cómo puede interpretarlo. Más que el hecho concreto y la conducta concreta es la relación y el contexto lo que lo convierte en patóge- 
no... Por eso tenemos que estar más atentos a las formas de relación y a los contextos: si no, a menudo nos veriamos buscando y buscando "abusos sexuales"... Con lo fácil que es que un niño "convenientemente interrogado" diga o recite casi lo que queramos...

(Silencio)

JLT: En este caso, ¿cómo entendéis que la madre no se entere, no sospeche nada, no venga a visitar a la hija si esta no va a verla?

Lola: Pero a lo mejor dijo que era de otro hombre.

Consuelo: No sé, salió que la habian violado, pero no ha dicho que era su tío hasta ahora. No sé, la historia es del 85 y no habia entonces tiempo de escribir nada, y lo que pone es “violación o depresión?".

JLT: Pero, antes de seguir, planteémonos qué piensa el grupo. ¿Este es un caso de Atención Primaria? ¿O no es sanitario o, como mucho, es propio de una asistencia privada o especializada, o de salud mental? Porque entonces estariamos como grupo correspondiendo a una perversión con otra: todos en plan voyeurista mirando los abusos sexuales sobre los que luego no vamos a hacer nada. Como aquellos directivos del programa norteamericano sobre abusos sexuales a niños que, tan preocupados ellos por el tema, fueron denunciados y condenados por abusos sexuales a algunas niñas a las que exploraban. Por ejemplo, podriamos sentir que como ella viene y se muestra tan "pobrecita", "cenicienta", no hay otro remedio que atenderla, aunque no sepamos qué hacer: una buena base para una relación masoquista por nuestra parte, para una identificación proyectiva con esa pareja. Eso iria en contra de que sea un tema propio del CAP. Por otro lado, a menudo la culpa extrema hace que se tienda a disociar: estas personas "escogen", entre comillas, la disociación. Pero es que en la asistencia privada, médica o de salud mental, es más fácil disociar: entre otras cosas, no se conoce a la familia, no se saben todos esos datos, no se hace entrevista familiar... ¿Qué cosa le estará tratando el psiquiatra si ella no le ha aclarado toda esta historia?: ¿la depresión, la relación sadomasoquista, la ansiedad, la culpa...? Para gran parte de esos temas no hay psicofármacos, y es con lo que has dicho que la están tratando...

Consuelo: Claro, esta señora se ha abierto con Alba, y hasta qué punto me lo puede contar a mi ella. Conmigo no se ha abierto en 10 años, no sé hasta qué punto yo le puedo hablar de esto.

JLT: Aqui, en el grupo, nos ha pasado: hemos pensado en incesto, y no está claro que sea ese el tema. Al menos, el tema principal. Es el foco moralista, que nos puede cegar bastante para la asistencia, por sentimientos que despierta en nosotros... Imaginaos descontextualizada esta información: ¿lo importante es el pene o el dedo en la vagina, o bien la relación de engaño y violencia y que se obtenga placer a costa del otro, con dominio y desprecio del otro? Esa es en realidad la perversión, no los orificios, las posturas o el género usado en la relación erótica. En el caso de esta pareja, desde luego, es un placer obtenido con culpa y a escondidas. La opción de obtener placer en la vida queda limitada 
probablemente para siempre porque el placer es culpable. Y más para una persona que recibió tal vez de niña el peor de los "castigos": ser arrojada a las "tinieblas exteriores", a la ausencia de madre (y de padre). Pero eso nos debe hacer pensar que Alba, la MIR, se va a ir, acaba su residencia en pocos meses, ¿y a quién irá esta señora cuando se vuelva a sentir mal, de su cuerpo o de sus angustias?

Consuelo: En mayo, junio, con los exámenes recaerá, como siempre.

JLT: ¿Y qué hay de particular en esa época, aparte de los exámenes?

Ma Carmen: La despedida.

JLT: La despedida, las separaciones. Recordad que es la época en que los maestros tienen que separarse de 20 o 30 niños, de 20 o 30 personas. $Y$ asi año tras año, para luego frecuentemente no volverlos a ver o casi... Y asi, año tras año... Despedirse de niños, despedirse de un hijola, despedirse de niños... Es un impacto. ;Cuánto trabajo tienen los maestros en este mes! Pero, sobre todo, mental. Sobre todo, si se piensa en lo difícil que es la separación. Y más para algunas personas como esta: tanto por experiencia vital como por estructura de personalidad. Como en nuestro trabajo: si fuéramos cambiando de pacientes continuamente, iqué daño nos hariamos a nosotros y a los pacientes! Hay que pensar que son relaciones y relaciones rotas.

Alguien: Además, está deprimida... Y yo creo que incluso puede intentar salir de todo esto suicidándose...

JLT: El tema de la autonomía y el tema del suicidio. Según las estadísticas, si es abusada en la infancia, dos veces y media más de probabilidad de suicidio como mínimo. Si, además, perdió a sus padres - no solo físicamente, pero si afectivamente-, otro tanto. Por eso si que parece que se trata de un caso que, aunque muy complejo, si que hay que atender, o, al menos, enfocar, en nuestra asistencia pública comunitaria.

Consuelo: Sí, desde luego. Además, está claro: si viene al Centro, si la estamos viendo cada dos por tres, por las somatizaciones, la ansiedad...

JLT: $Y$ eso nos vale para recordar que debajo de las somatizaciones hay problemas de personalidad y sufrimiento no siempre de este tipo, pero casi siempre dificiles de elaborar.

Alfons: A lo mejor piensa que no hay posibilidad. Las relaciones las habrá mantenido durante más tiempo, se supone, y más después del fallecimiento de la tía. ¿No os ha dicho si toma anticonceptivos?

Consuelo: No lo sé.

Alfons: Esta forma de obtener placer, el establecimiento de esta relación tan patológica... Porque podría haberse ido, pero se ha mantenido alli. Si se hubiera casado con otro hombre, a lo mejor esta historia de depresiones sería de otra forma.

Lola: Sentimentalmente no era libre.

JLT: La indefensión aprendida, que dicen los cognitivistas. Tal vez la compulsión al sadomasoquismo se lo ha impedido. 
Consuelo y Tonia miran la historia clínica, que han traído a la sesión, algo que poquísimas veces nos ha sucedido en decenios de trabajo con grupos "tipo Balint". (Seguro que tiene que ver con las inquietudes que despierta el tema). Comprueban en ella que a la ginecóloga le habían dicho lo mismo: que había muerto un hijo de tres días y que ella tenía 22 años.

Marita: ¿A los 22 años estuvo encerrada en casa durante 9 meses?

Tonia: Pero en un pueblo no es tan extraño que pase así...

JLT: Solo que no era un pueblo...

Isabel: Yo no saldría.

JLT: Pensad que ella le ha prometido en el lecho de muerte a la tía, su competidora, que no abandonaría a su tío, su pareja "perversa". Tal vez la culpa que la domina es tan insoportable que tiene que purgarla asi, para siempre, "hasta la muerte".

Conchi: Nos planteamos si lo había dado o se lo habian quitado.

Marita: Con 22 años, lo ha dado.

Consuelo: Pero el hijo no es lo que la atormenta.

Marita: Sí, ipero que, con 22 años, diga que no la dejaban salir de casa!....

JLT: En el grupo parece que ahora estamos en una actitud un poco detectivesca. Vosotras incluso estabais investigando en la historia. ¿Qué pasó en realidad? Pero ¿en qué realidad? Con todo lo patógeno que hay en esta mujer, dar por muerto al hijo puede ser otra disociación más. Pero fijarnos en las relaciones y en la fantasía, en qué hay en la mente y las relaciones y no solo en la conducta, es tal vez lo unico que puede darnos una pista, además de ayudarnos a evitar el voyeurismo detectivesco, el melodrama, el folletin... Para ella, el hijo "murió". En su mente, tal vez incluso "lo mató". Ya es suficientemente terrible la idea tratándose del unico hijo. Por otra parte, ¡el que sepamos muchos datos va a ayudar a la paciente? :Para ayudarla necesitamos muchos datos? Probablemente, haya habido o no abusos, hay perversión. Asi ha crecido y esta es la situación patógena. Estar creciendo con quien necesitas, porque no te puedes ir a otra parte, pero que sabes y experimentas que es un abusador. Un abusador sobre todo emocional, y tal vez sexual. Además, ya padeció un abandono, una separación traumática bien temprana: su madre la dejó con sus tios. En cambio, a sus hermanos, no. El diagnóstico no es difícil: como decíais, casi seguro que padece una depresión. Pero lleva con ella 20 años y no sale adelante. Y ya sabemos que cuando ocurre esto es que hay algo más... ¿Qué creéis que puede ser?

Lola: Es muy confusa.

Magda: Perversión.

JLT: O trastorno de personalidad. Pero si decis "perversión", ¿qué tipo de perversión?

$\mathbf{M}^{\mathrm{a}}$ Carmen: ¿Sadomasoquismo?

JLT: Posiblemente, ese es el trasfondo mental y relacional. $O$, al menos, lo parece. $Y$ eso significa que por muchos medicamentos que le den, poco van a mejorarla en las épocas peores. Incluso puede utilizarlos para suicidarse. Lo típico sería que realizase intentos de 
suicidio: en una persona que se queda atada a lo que le hace daño... ¿Qué es lo que hace más daño que el suicidio? Y, además, esta paciente nos cuenta a las claras cómo se queda culpablemente atada a lo que la daña: "Prometi en el lecho de muerte que lo cuidaría". Incluso queda más claro todo, más significativo, con la descripción de la médico de urgencias: los "cogió" peleándose encima de una cama, con su fusión del simbolismo sexual y la agresión en esta situación...

Lola: ¿Y cómo se puede ayudar a estas personas?

JLT: Gracias a que podemos pensar sobre el tema, ahora podemos ver lo difícil que es y por qué el equipo va a tener que usar de mucha contención y poca acción. Porque "si las cosas van bien, tienen que ir mal después", porque "soy muy culpable", va a sentir ella. Probablemente, primero es la culpa, y luego el odiar tanto a su madre porque la abandonó: ha quedado vinculada a seres que necesita pero que odia. En casos asi los psicofármacos ayudan poco: solo puntualmente, en las fases depresivas que probablemente desarrollará. Pero no pueden cambiar esta forma de relación, tan cerrada. "Si las cosas van bien, tienen que ir mal". Cuando la tía murió, podia haberse ido, pero no le cupo en la cabeza; en vez de eso, promete que se quedará con el tío a cuidarle "hasta que muera". $Y$ ahora, con la casa puesta, la pone al nombre del tío. Solo hay una vía, aparte de los fármacos, que puede ayudar en los momentos más depresivos y en los demás: un cierto apoyo psicológico prudente. Pero ¿quién puede proporcionárselo a esta paciente? ¿Un psicoterapeuta especializado? ¿Vosotros mismos? No está claro, porque, ya de entrada, ¿quién se lo dice, quién la deriva? Como habéis dicho, tal vez primero tendriais que hablarlo los tres miembros de la consulta para ver quién se hace cargo de este intento más psicológico y quién de otros aspectos de la paciente. También, para decidir cómo tratar el tema de la confidencialidad y de la posible denuncia: si haces como que no sabes nada, si no dices nada, ¡es que estás muerto como el niño, eres como un cajón sin fondo, eres un receptáculo en el que nada resuena? Porque ella ha hablado con alguna de vosotras (por cierto: vosotras, femenino, aliadas). Si mentís, o ya no lo tenéis en cuenta, en realidad la engañáis. Es el mismo tipo de relación que ella vivirá como sádica: no la ayudaréis. "Otra que parece que si, pero es que no".

Consuelo: Tendriamos que decirle que como equipo lo sabemos y lo tratamos...

JLT: Probablemente sí, al menos si pensáis intervenir, recoger sus confidencias actuales, intentar ayudarla. Pero previamente deberéis tener claro lo que queréis hacer. Por ejemplo, antes deciais que lo mejor es que la reciba Alba, que al fin y al cabo es a quien declaró la situación, pero esta situación no se arregla en seis meses... Ni, posiblemente, en años... Y Alba, como MIR que es, se va en seis meses... Y hay que trabajar, colocarse en la situación como si, afortunadamente, fuerais a tener a esta paciente $y$, en general, a los pacientes de APS, durante años. Digo afortunadamente porque es posible que abandone en momentos, que intente el suicidio o que actúe en forma dañina... Además, este tipo de relaciones erotizadas intrafamiliares no son tan infrecuentes... sino relativamente fre- 
cuentes, sobre todo en las familias con más psicopatología. Por ejemplo, en familias con psicosis, en depresiones graves, en sadomasoquistas graves... Ya incluso el mismo Freud habia hablado de ello...

T.S.: Valdría la pena decirle que cambiara de trabajo. Yo sigo pensándolo.

Ma Carmen: No. ¿Qué haría entonces? ¿Y cómo explicárselo? Se necesita mucho más tiempo y elaboración...

Alfons: Yo estoy igual de perdido.

Ma Carmen: Primero has de hablarlo con ella, que te lo explique y que no te horrorices.

Consuelo: Tiene unas ganas horrorosas de hablar.

Alfons: $Y$ animarla a que explique esto. Aunque sea a su psiquiatra, pero que se lo explique a alguien.

Lola: Se le puede preguntar si su psiquiatra lo sabe, porque a lo mejor a él se lo ha contado.

JLT: Ciertamente, es un tema básico, porque si no, tendremos otra nueva vía de disociación: a cada equipo le cuenta unas cosas, lo cual le sirve para seguir disociando internamente. Claro que el recurso al psiquiatra puede ser otra forma de "esperanza mesiánica" de todos nosotros, del grupo. Si el psiquiatra es de orientación biologista no hará nada especifico con este dato; si es de orientación psicoanalitica, relacional o ecléctica, tal vez puede ayudarla tanto en el enfoque como en el tratamiento. La catarsis, vaciarse, hablar y hablar, por si misma suele valer de poco. Pero, en este caso, hablar del tema, que haya hablado del tema, no es solo catarsis: no es una histérica que "se vacía" con el nuevo espectador. Lo ha tenido callado durante más de 20 años. Ahora que se ha abierto, ayudar a que hable, a que continúe abriéndose con confidencialidad es en si mismo terapéutico... Sobre todo si se la escucha con respeto y de forma no moralista... Y con quien lo ha hecho es con Alba: tal vez por eso sentis que es con Alba con quien deberia continuar. El caso es difícil, desde luego. Da miedo meterse en él. Pero también hemos de ser tolerantes con nuestras insuficiencias y errores. Nadie va a "curarla", pero si se la puede ayudar a vivir menos mal... Sobre todo, si somos capaces de realizar esa labor que yo llamo de "ablandar el superyó", ese superyó sádico y cruel que ha hecho que prometa en el lecho de muerte que cuidará a su tío... Y con el odio implícito en la frase "hasta que se muera". Nadie la obligaba: solo la crueldad, el sadismo interno de su superyó, esa rigidez en expiar las culpas...

Pediatra 1. ¡Qué difícil! iiPuff!! Y eso, ¿cómo se hace?

JLT. Probablemente se trata de hacer pequeñas intervenciones que "ablanden el superyó", ayudarle a que no se sienta tan obligada; a sentir que todo, menos la muerte, tiene arreglo. Incluso su vida anterior y la relación con su tío... Aunque sea separándose de él; aunque sea rompiendo con él o incluso denunciándolo.... Aunque lo del hijo no tenga ya remedio. Al menos, que sienta que la oimos sin repugnancia ni temor, que no es 
tan repulsiva como ella a veces se ve y el grupo puede haberla sentido... Y las intervenciones tenemos que creérnoslas nosotros primero, claro. Si no, no valen para nada. Por eso es tan importante primero haberlo hablado en grupo, haber disuelto un poco en el grupo la "moralina", el superyó grupal o de equipo excesivo y justiciero...

Alfons: Pero eso es muy difícil. Yo enseguida he pensado de este hombre: ;Qué tío tan horrible!... Creo que le siento culpable, le he puesto la culpa...

JLT: En estos casos a veces vale la pena pensar dónde está el niño desvalido... Qué parte del consultante o de la consultante está desvalida, asustada, desorientada... Cuando un hombre te molesta o repugna tanto en la consulta que sientes que no puedes seguir con él, claro está que se le puede pedir que se cambie de médico, pero también puede ayudarnos antes el intentar conectar con la parte "niño desvalido" de ese paranoide, de ese sádico, de ese actuador, de ese perverso... Con lo difícil que a veces es. En este caso, en ella está claro: el abandono. Hay una niña abandonada que, en lo inconsciente, se culpa por su abandono, y se obliga a "querer" a quien la maltrata. Lo sola que ha estado ella durante años. Ella ya se persigue: hasta que él se muera, ella estará allí, atada. Y entonces, todavía para ella misma será la portadora de la culpa. Y él... Pues de él sabemos poco, тиу росо...

Consuelo: Pero algo debe quererla, porque no viene nunca por él mismo, pero sí que la acompaña siempre. No dice nada, está muy serio, pero viene siempre. Claro que tal vez sea para vigilarla, pero creo que no, que no es solo por eso, que también algo la quiere... Ahora, con la pelea, ella se ha ido de la casa, ya no vive con él, pero está pensando en volver.

JLT: Pero nosotros, por hoy, lo tenemos que dejar aqui, porque es la hora...

He ahí una muestra, creo que ilustrativa, de los elementos de contención y formativos de una sesión de grupo "tipo Balint", con una tema especialmente difícil y delicado, tanto desde el punto de vista relacional y ético como desde el punto de vista profesional, técnico y deontológico, máxime hace más de una decena de años. Una muestra de cómo un grupo de profesionales debe afrontar un tema grave, para el que nunca fueron formados; un asunto que está dando grandes trabajos, sufrimientos y gastos en la atención comunitaria y que, por ende, no está claro que pueda ser mucho mejor atendido por la asistencia súper-especializada..., a la que, encima, probablemente, la consultante y el no-consultante se negarán a acudir.

Ante situaciones así, o se aumenta la "capacidad de pensar", la formación y la capacidad de contención de los profesionales, o la situación puede dar paso no solo a la colisión entre los dos "asegurados", sino entre uno o dos de ellos y el equipo profesional. Hasta ahora, ha habido una compleja colusión basada en la disociación, la de-negación, la negación y la mentira directa. El resultado ha sido una relación sumamente frustrante e ineficaz para todos. Sin embargo, en el futuro será una relación esencialmente inestable, lo que significa que, tarde o temprano, la colusión 
puede dar paso a la colisión. Y mucho más si tenemos en cuenta la situación básica en la que a menudo se mueven los profesionales sanitarios en la actualidad: suelo definirla como el amplio abanico que va desde la colusión a la colisión (1, 6-8). Y, a mi entender, ese es uno de los motivos por los cuales bastantes médicos actuales se sienten a menudo "tan infelices", como recordaba no hace mucho un editorial del British Medical Journal (9).

Es una situación social y sanitaria que todos podemos contribuir a cambiar, y a la que iban dirigidos precisamente los primeros "grupos Balint". El exceso de insatisfacción, frustración e infelicidad en el trabajo asistencial sigue siendo uno de los objetivos fundamentales de tales grupos (10-13). Con el valor ańadido de que con ellos tratamos de cambiar una situación frustrante basándonos en la reparatividad, en la capacidad de reparar de individuos y grupos. Y con una técnica grupal basada en la reparatividad y en la solidaridad en grupo. Reparatividad y trabajo grupal solidario: dos elementos fundamentales para un cambio ya no solo sanitario, sino social. Dos puntos de partida concretos en este ámbito para desarrollar una idea que suelo reproducir a menudo: "Otro mundo mejor es posible, pero hemos de comenzarlo a partir de este".

\section{BiBLIOGRAFÍA}

(1) Tizón JL. ¿Cómo mejorar la perspectiva integrativa de los médicos clínicos?: una revisión de los grupos Balint y los grupos de reflexión (I). Rev. Asoc. Esp. Neuropsiq. 2019; 39(136): 19-43.

(2) Tizón JL. Psicopatología del poder: un ensayo sobre la perversión y la corrupción. Barcelona: Herder, 2015.

(3) Tizón JL, Ciurana R, Fernández MC (compiladores). Libro de casos: promoción de la salud mental desde la atención primaria. Barcelona: Herder, 2011.

(4) Fernández MC, Herrero S, Buitrago F, Ciurana R, Chocrón L, García-Campayo J, et al. Violencia doméstica. Madrid: Ministerio de Sanidad y Consumo, Dirección General de Salud Pública - SEMFYC (Sociedad Española de Medicina de Familia y Comunidad) - PAPPS (Programa de Actividades Preventivas y de Promoción de la Salud), 2003.

(5) Buitrago F, Ciurana R, Chocrón L, Fernández MC, García-Campayo J, Montón C, et al. Prevención de los trastornos de la salud mental en atención primaria. Actualización PAPPS 2018. Aten Primaria. 2018;50(Supl 1):83-108.

(6) Tizón JL. Apuntes para una psicopatología basada en la relación. Barcelona: Herder, 2019.

(7) Tizón JL. Los nuevos modelos asistenciales en medicina: una visión a partir de algunos de sus fundamentos psicológicos y epistemológicos. Revisiones en Salud Pública 1995,4: 57-83. 
(8) Tizón JL, Clèries X, Daurella N (compiladores). ¿Bioingeniería o medicina?: el futuro de la medicina y la formación de los médicos. Barcelona: Red Ediciones, 2012.

(9) BMJ. Editorial. Why are doctors so unhappy? BMJ 2001; 322: 1073-1074.

(10) Rabinowitz S, Kushnir T, Ribak J. Preventing burnout: increasing professional self efficacy in primary care nurses in a Balint Group. AAOHN J. 1996;44(1):28-32.

(11) Kjeldmand D, Holmström I. Balint groups as a means to increase job satisfaction and prevent burnout among general practitioners. Ann. Fam. Med. 2008; 6(2):138-145.

(12) Tizón JL. Desgaste profesional y "burnout": realidades, burbujas y oxímoros. En: Espino A. (coordinador). Vida laboral, estrés y salud mental. Madrid: Asociación Española de Neuropsiquiatría, 2012; pp. 183-223.

(13) Tizón JL, Gracia P, Larripa A, Artigue J, Casajuana J. Preventive care for burnout: General Practitioners pilot program in Barcelona. Health. 2013; 5(6A2). 